\title{
Circuit
}

Musiques contemporaines

\section{Dans le ventre de la musique actuelle}

\section{Danielle Palardy Roger}

Volume 6, numéro 2, 1995

Musique actuelle?

URI : https://id.erudit.org/iderudit/902129ar

DOI : https://doi.org/10.7202/902129ar

Aller au sommaire du numéro

Éditeur(s)

Les Presses de l'Université de Montréal

ISSN

1183-1693 (imprimé)

1488-9692 (numérique)

Découvrir la revue

Citer cet article

Palardy Roger, D. (1995). Dans le ventre de la musique actuelle. Circuit, 6(2),

11-14. https://doi.org/10.7202/902129ar d'utilisation que vous pouvez consulter en ligne.

https://apropos.erudit.org/fr/usagers/politique-dutilisation/ 


\section{Dans le ventre de la musique actuelle Danielle Palardy Roger}

Dans le ventre de la musique actuelle, il y a du métal, des arbres, du rock, des oiseaux, du jazz, des avions, des fusils, des poulies, des avalanches, des graffiti, des crécelles, des blenders, des hurlements, des corps qui bougent, des yeux qui regardent, des bouches qui grimacent et qui rient, des patentes, des ordinateurs et des haut-parleurs.

Le son voyage à travers le temps plus lentement que la lumière

Serait-ce la raison du retard de la musique sur les arts qui sont reliés à la lumière

Dans le ventre de la musique actuelle, il y a beaucoup d'imprévus, de ruptures, de collages, d'improvisations, de fausses notes, de voix imparfaites, d'impuretés, de matières brutes et brutales, de stridence, de stress, de dissonances, de dissidence.

Le son voyage plus lentement que la lumière

C'est tout calculé

Le son voyage à la vitesse de $332 \mathrm{~m} / \mathrm{s}$

La lumière à plus de $300000 \mathrm{~km} / \mathrm{s}$

Oui, elle a un ventre la musique actuelle; elle a un corps cette musique ; elle a une tête sur les épaules mais elle a aussi un cul. La musique actuelle est vulgaire, criante, choquante et impure; elle est crue. En plus, elle ne va pas à l'école, c'est une délinquante, une iconoclaste et une prolétaire.

La musique et ses formes diffusées sont tellement contrôlées par les médias de types capital/commerce standardisés que nous ne savons plus ce qu'est la musique ni comment celle-ci se développe aujourd'hui en tant qu'art art de l'organisation des sons.

Est-ce le son qui est lent ou l'oreille qui est lente à déchiffrer le son 
J'imagine que

la lumière devant être reflétée par la matière pour être vue

le son doit être revibré pour être entendu

Est-ce le son qui est lent ou l'oreille

Ou serait-ce l'œil qui est plus rapide que l'oreille

Refléter la lumière s'avérant plus facile que refléter le son

Le son exigerait-il plus de la matière que la lumière

Le son transformant plus la matière

Dans son ventre, il y a de l'incertitude et beaucoup de pauvreté. Très peu de moyens. Pas beaucoup de reconnaissance. II y a beaucoup d'autodidactes et de défroqués. II y a des hommes surtout, mais des femmes aussi.

La musique tend à englober

plus d'informations, plus de relations

qu'elle ne l'a encore fait au cours des siècles précédents.

Jamais autant de données n'ont été en présence

dans un même espace-temps.

Rares sont ceux qui enseignent. Parce qu'ils ont dit non. Non aux écoles, non aux commerces. Dans le ventre de cette musique, il y a une planète entière blanche, rouge, noirè, jaune et métissée qui dit non à l'engourdissant dogme de l'obéissance historique.

Le son touche le corps

jusque dans ses plus petites particules

Particules de viscères

Le son touche la matière et s'installe dedans

Dorénavant le corps se souviendra du son,

de sa hauteur, de sa longueur

et pourra même le reproduire

Pouvons-nous reproduire la lumière

Dans la musique actuelle il y a trop de libertés; trop de présences, trop de changements, trop de mouvements, trop de rythmes. Dans le ventre de la musique actuelle il y a trop de bruits.

L'harmonie et le rythme sont des relations vivantes

ce n'est pas parce que nous les avons étudiées

calculées, classées

que nous avons arrêté leurs mouvements

L'harmonie est du domaine de l'infini

aucun son ne peut en être exclu

son ampleur est telle qu'elle dépasse encore

le champ de l'imagination auditive

tous les sons cohabitent dans un même instant 
ils sont parcelles divisions du son

$\|$ en va de même pour les rythmes

tous sont possibles simultanément

Ils sont si justement là en ce moment, présents

régissant tous les mouvements

Dans le ventre de la musique actuelle il y a des instrumentistes qui composent et partagent avec d'autres instrumentistes qui composent le plaisir de jouer ensemble leurs compositions.

Quand une onde sonore

pénètre le corps par l'oreille

elle est immédiatement

revibrée par sa membrane tympanesque

ce qui fait marteler les osselets

Ce bruit est ensuite dirigé

à travers les eaux labyrinthiques

jusqu'au fin fond du rocher encéphalique

II se gravera finalement dans le corps tout entier

La musique actuelle a un trop-plein dans son ventre vide.

Extraits de ...réflexions inutiles sur un art de l'entente... 


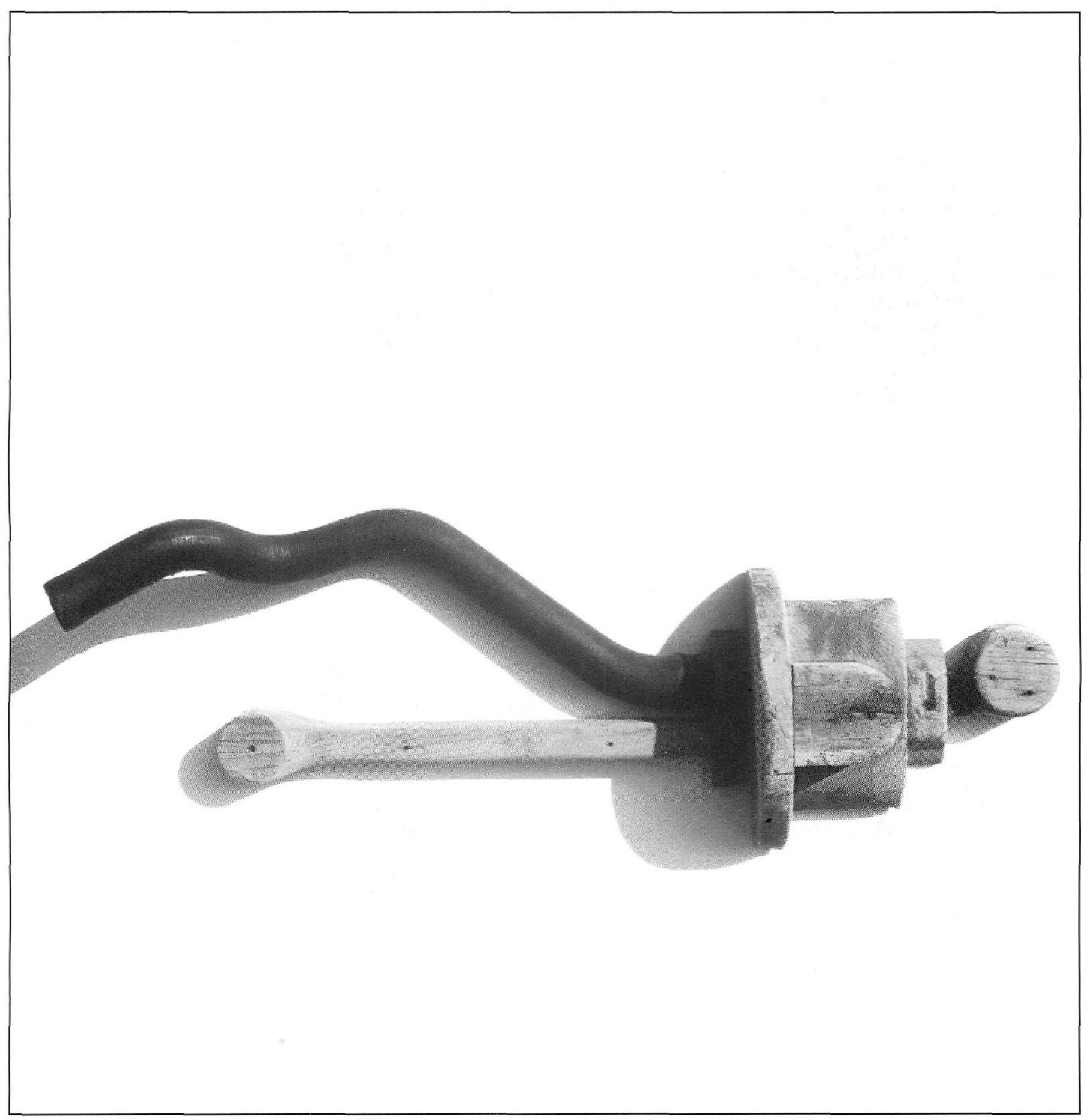

